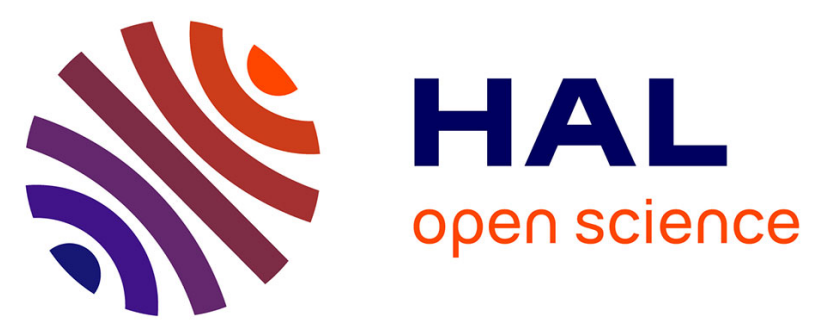

\title{
Enzyme Encapsulation in Mesoporous Metal-Organic Frameworks for Selective Biodegradation of Harmful Dye Molecules
}

Effrosyni Gkaniatsou, Clémence Sicard, Rémy Ricoux, Linda Benahmed, Flavien Bourdreux, Qi Zhang, Serre Christian, Jean-Pierre Mahy, Nathalie

\author{
Steunou
}

\section{To cite this version:}

Effrosyni Gkaniatsou, Clémence Sicard, Rémy Ricoux, Linda Benahmed, Flavien Bourdreux, et al.. Enzyme Encapsulation in Mesoporous Metal-Organic Frameworks for Selective Biodegradation of Harmful Dye Molecules. Angewandte Chemie International Edition, 2018, 57 (49), pp.16141-16146. 10.1002/anie.201811327 . hal-03113635

\section{HAL Id: hal-03113635 \\ https://hal.science/hal-03113635}

Submitted on 18 Jan 2021

HAL is a multi-disciplinary open access archive for the deposit and dissemination of scientific research documents, whether they are published or not. The documents may come from teaching and research institutions in France or abroad, or from public or private research centers.
L'archive ouverte pluridisciplinaire HAL, est destinée au dépôt et à la diffusion de documents scientifiques de niveau recherche, publiés ou non, émanant des établissements d'enseignement et de recherche français ou étrangers, des laboratoires publics ou privés. 


\title{
Enzyme encapsulation in mesoporous Metal-Organic Frameworks for selective biodegradation of harmful dye molecules.
}

\author{
Effrosyni Gkaniatsou, ${ }^{[\mathrm{a}]}$ Clémence Sicard, ${ }^{*[\mathrm{a}]}$ Rémy Ricoux, ${ }^{*}{ }^{[\mathrm{b}]}$ Linda Benahmed, ${ }^{[\mathrm{a}]}$ Flavien Bourdreux, ${ }^{[\mathrm{a}]}$ \\ Qi Zhang, ${ }^{[a]}$ Christian Serre, ${ }^{[c]}$ Jean-Pierre Mahy, ${ }^{[b]}$ Nathalie Steunou ${ }^{[a]}$
}

In memory of Gérard Férey

\begin{abstract}
Microperoxidase-8, a small, peroxidase-type enzyme was successfully immobilized into nanoparticles of the mesoporous and ultra-stable MIL-101(Cr). The immobilized enzyme retained fully its catalytic activity and exhibited enhanced resistance to acidic conditions. The biocatalyst was reusable and showed a long-term stability. By exploiting the properties of the MOF's framework, we demonstrated, for the first time, that the MOF matrix could act in synergy with the enzyme (Microperoxidase-8) and enhance selectivity the oxidation reaction of dyes. The oxidation rate of the harmful negatively charged dye (methyl orange) was significantly increased after enzyme immobilization, most likely due to the preconcentration of the methyl orange reactant due to a charge matching between this dye and the MOF.
\end{abstract}

Enzymes are biomolecules with remarkable catalytic properties essential for specific applications, such as production of biochemicals and biofuels, and for biosensing and bioremediation purposes. ${ }^{[1]}$ Despite many advances in enzyme engineering, they remain expensive and/or fragile entities. As a result, their use in industrial context often requires their immobilization on a solid support to increase their stability and recovery. Many supports have been developed in the last decades, including, but not limited to, biopolymers/synthetic polymers, sol-gel materials, mesoporous silica, carbon materials, ${ }^{[2]}$ and recently Metal-Organic Frameworks (MOFs).$^{[3]}$ These latter are a class of crystalline hybrid porous materials characterized by a vast chemical functionality, exhibiting a large variety of structural features (surface area, pore size, shape, flexibility...). These have sparked a great interest in many applications such as gas storage and separation, heat transfer, biomedicine, sensing and catalysis, among others. ${ }^{[4]}$ As immobilization matrices, they seem promising since the

[a] E. Gkaniatsou, Dr. C. Sicard, F. Bourdreux, L. Benhamed, Dr. Q. Zhang, Pr. N. Steunou

Institut Lavoisier de Versailles, UVSQ, CNRS, Université ParisSaclay, 45 avenue des Etat-Unis, Versailles, France E-mail: clemence.sicard@uvsq.fr

Dr. Q. Zhang current address: Collaborative Innovation Center of Advanced Energy Materials, School of Materials and Energy, Guangdong University of Technology, Guangzhou 510006, China [b] Dr. R. Ricoux, Pr. J-P. Mahy

Laboratoire de Chimie Bioorganique et Bioinorganique, Institut de Chimie Moléculaire et des Matériaux d'Orsay, UMR 8182, Université Paris Sud, Université Paris-Saclay, Orsay, France. E-mail: remy.ricoux@u-psud.fr

[c] Dr. C. Serre

Institut des Matériaux Poreux de Paris, FRE 2000 CNRS Ecole Normale Supérieure, Ecole Supérieure de Physique et de Chimie Industrielles de Paris, PSL research university, Paris, France.

Supporting information for this article is given via a link at the end of the document. biological activity of immobilized enzymes was preserved, even under unnatural environments (high temperature, solvent), and long-term stability was observed. ${ }^{[5]}$ Among the MOF properties, their hybrid nature and multimodal porosity have appeared as key parameters for successful biocatalysis, as they allow efficient mass transfer, and eventually the co-entrapment of cofactors. ${ }^{[6]}$ In few studies, the MOF matrix acted as a selective diffusion barrier of reactants by size exclusion. ${ }^{[3,7]}$ Despite these encouraging results, the role of MOF materials on the bioreactor performances has so far been mostly limited to a stabilizing host scaffold.

Microperoxidase-8 (MP8, Figure 1a), is a mini enzyme that contains a heme prosthetic group together with amino-acid residues 14-21 of horse cytochrome c. This heme-octapeptide simultaneously combines two types of catalytic activities: a high peroxidase-like activity as well as a cytochrome P450-like activity. ${ }^{[8]}$ However, it suffers from several limitations. Deterioration of the catalytic activity occurs both under harsh conditions (acidic pH or oxidative media) and at MP8 concentrations higher than $2 \mu \mathrm{M}$ due to the heme dimerization. ${ }^{[9]}$ Moreover, the distal coordination position of the iron atom of MP8 is completely exposed to the solvent and, thus lacks of a specific catalytic pocket, which results in low substrate selectivity. Herein, we show that the encapsulation of MP8 in the mesoporous cages of a polycarboxylate MOF (MIL-101(Cr)) can be a valuable strategy to enhance the catalytic activity of MP8 under acidic or oxidative conditions. We also demonstrate that the MOF matrix not only performs as a protective host support able to maintain long-term, recyclable catalytic activity but can also enhance the catalytic performance of the bioreactor due to its excellent adsorption properties. Furthermore, since very large amounts of commercial dyes are produced in textile and paper industries, ${ }^{[10]}$ which makes their removal crucial for environmental matters, we targeted the oxidative degradation of model organic dyes (harmful Methyl Orange). Remarkably, we demonstrated that the MOF-based matrix can supplement a higher reaction rate to the enzymatic catalytic reaction due to the selective substrate pre-concentration through a charge-based mechanism.

MP8 was obtained by the hydrolytic digestion of cytochrome c (synthesis conditions in SI and characterization of purified MP8 by MALDI-TOF mass spectrometry and UV-Vis spectroscopy in Figure S1). ${ }^{[11]}$ MIL-101(Cr) was selected as an immobilization matrix due to its high chemical stability and its very large hierarchical porosity (cages of $2.9 \mathrm{~nm}$ and $3.4 \mathrm{~nm}$ ), ${ }^{[12]}$ compatible with MP8 size $(<3.3 \times 1.1 \times 1.7 \mathrm{~nm})$, while retaining accessible diffusion pathways for substrates, once the enzyme is immobilized. Notably, the windows to access the cages are smaller in sizes $(1.2 \times 1.6 \mathrm{~nm}$ and $1.2 \mathrm{~nm})$, but it has previsouly been shown that heme-based enzymes could undergo conformational changes similar to translocation mechanisms to 


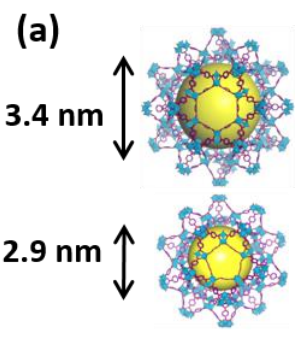

nanoMIL-101 cages

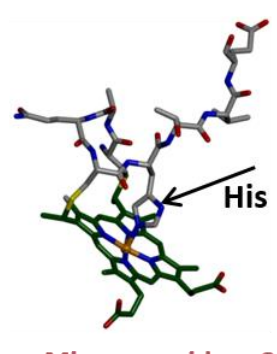

Microperoxidase 8 $(3.3 \times 1.1 \times 1.7 \mathrm{~nm})$ (b)

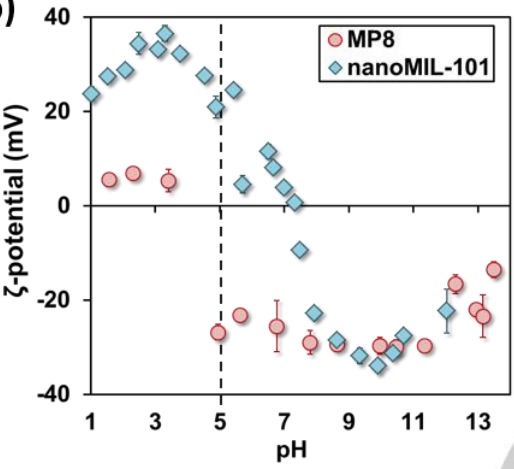

(c)

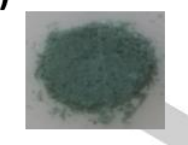

nanoMIL-101

(d)

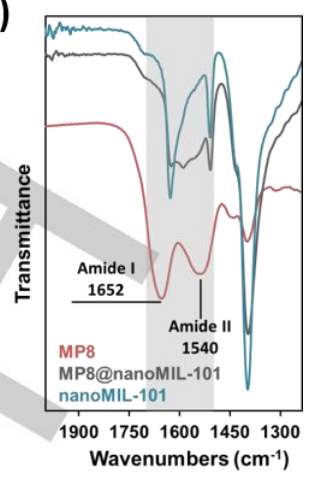

Figure 1. (a) Cages of nanoMIL-101 and molecular structure of microperoxidase 8 containing an Fe(III) porphyrin and the amino acid residues 14 to 21 of Cytochrome c. The imidazole group of the histidine residue (His18) acts as the fifth axial ligand of the Fe(III) (Structure data were obtained from the solution structure of PDB 1OCD) ${ }^{[13]}$; (b) $\zeta$-potential measurements of nanoMIL-101 (blue square) and MP8 (red circles) as a function of pH; (c) Images of the powder of nanoMIL-101 (top) and MP8@nanoMIL-101 (down); (d) FT-IR spectra of MP8 (red), MP8@nanoMIL-101 (grey) and nanoMIL-101 (blue).

diffuse through smaller windows into larger voids. ${ }^{[14]}$ A simple microwave assited hydrothermal synthesis was employed (synthesis conditions in SI) to obtain nanoparticles of MIL$101(\mathrm{Cr})^{[15]}$ and thus favour diffusion kinetics. ${ }^{[16]}$ To take full advantage of the impact of the framework and provide an enhanced protection, a 3-dimensional confinement of the enzyme was preferred over a surface immobilisation. The encapsulation was accomplished by simply mixing a solution of nanoMIL-101 with a solution of MP8 for $48 \mathrm{~h}$ at $37^{\circ} \mathrm{C}$. To ensure strong electrostatic interactions between the MP8 molecules and the MOF particles, the $\mathrm{pH}$ of the mixture was adjusted to 5 , where the MIL-101 nanoparticles are positively charged and MP8 negatively charged as shown in Figure 1b. The immobilized catalyst (MP8@nanoMIL-101) was washed with water to remove MP8 molecules that may have remained weakly adsorbed on the outer surface of nanoMIL-101. The presence of MP8 within the powder could be directly observed by the resulting colour change from green to brown-reddish as illustrated in Figure 1c. The MP8@nanoMIL-101 was characterized by Powder X-Ray Diffraction (PXRD, Figure S2), showing that the crystalline structure of MIL-101(Cr) was preserved after encapsulation. The immobilization of MP8 was confirmed by the presence of characteristic vibrations bands of amide I and II in FTIR spectrum of MP8@nanoMIL-101 displayed in Figure 1d. The amount of enzyme within MP8@MIL-101 was determined to be of circa $5 \% \mathrm{w} / \mathrm{w}$ by Inductively Coupled Plasma Atomic Emission Spectroscopy (ICP-AES) based on the $\mathrm{Fe} / \mathrm{Cr}$ ratio (sample preparation in $\mathrm{SI}$ and detailed amounts in Table S1 and S2). The same MP8 content was confirmed by Energy Dispersive X-Ray (Table S3) and with UV-Vis spectra of the remaining MP8 quantities in the supernatant (Table S4). NanoMIL-101 and MP8@nanoMIL-101 were further characterized by nitrogen porosimetry at $77 \mathrm{~K}$ (Figure S3), leading to BET surface areas of $2550 \mathrm{~m}^{2} / \mathrm{g}$ and $1510 \mathrm{~m}^{2} / \mathrm{g}$, respectively. This loss of surface area of about 1000 $\mathrm{m}^{2} / \mathrm{g}$, i. e. $39 \%$, was consistent with the presence of MP8 within the pores of the MOF. A similar content of MP8 $(5 \% \mathrm{w} / \mathrm{w}$, see Table S1 and S2) was also obtained when larger particles micrometer size) of MIL-101 were considered (Figure S4), thereby suggesting that MP8 molecules were inserted within the porosity and not adsorbed at the outer surface. To further confirm the confinement of MP8 molecules inside the pores of nanoMIL-101, the accessibility of the Fe(III) atom of MP8 was assessed by following the coordination of an imidazole molecule $(\mathrm{ImH})$ to the sixth axial position of the $\mathrm{Fe}(\mathrm{III})$ on the distal face of the heme (Figure 1a). ${ }^{[17]}$ As seen in Figure S5a and S6a, with increasing imidazole concentrations, the maximum absorbance wavelength of MP8 Soret band shifts gradually from $396 \mathrm{~nm}$ to $404 \mathrm{~nm}$, as a result of the complexation reaction of the $\mathrm{ImH}$ with the heme moiety of MP8, forming MP8 $(\operatorname{ImH}) \cdot{ }^{[18]}$ To reach saturation of MP8(ImH) complex formation, MP8@MIL-101 reacted with almost 7 times more imidazole than the free MP8 (3.7 $\mathrm{mM}$ and $0.57 \mathrm{mM}$, respectively). This higher amount suggests diffusional limitations, in agreement with the inclusion of MP8 inside the porosity of nanoMIL-101. Importantly, the calculated dissociation constants of the MP8 $(\mathrm{ImH})$ complex were 0.37 and $0.10 \mathrm{mM}$ (Figure S5b and S6b) for MP8@nanoMIL101 and free MP8, respectively. These relatively close values indicate that the MP8 binding site are not altered and remain fully accessible after encapsulation.

No peroxidase activity was detected in the presence of nanoMIL-101 alone as catalyst. Both free and immobilized MP8 catalyzed the oxidation of ABTS showing similar trends with increasing both reaction rates and converted $A B T S$ amounts with increasing $\mathrm{pH}$. At $\mathrm{pH} 8$, the concentration of $\mathrm{ABTS}^{+}$was higher for immobilized MP8@nanoMIL-101. For the free MP8, as illustrated in Figure S9, the absorbance at $420 \mathrm{~nm}$ of ABTS ${ }^{+}$ reached a maximum and then decreased due to over oxidation. ${ }^{[19]}$ This phenomenon was not observed in the case of MP8@nanoMIL-101, which may result from stabilization of $\mathrm{ABTS}^{+}$through strong interactions (coordination on the $\mathrm{Cr}$ metal sites) with the MOF framework, as reported before for ABTS encapsulation into an iron mesoporous polycarboxylate based MOF. ${ }^{[6]}$ At pH 6-7, free MP8 oxidized higher amounts of ABTS than immobilized MP8@nanoMIL-101. On the opposite, at pH 5 the amount of $\mathrm{ABTS}^{+}$was higher for immobilized MP8@nanoMIL-101. Since high concentrations of $\mathrm{H}_{2} \mathrm{O}_{2}$ and acidic conditions are known to be detrimental to MP8 catalytic peroxidase activity, ${ }^{[20]}$ the protective role of the MOF matrix against such harmful conditions was further investigated by varying $\mathrm{H}_{2} \mathrm{O}_{2}$ concentration $(0.1-1.8 \mathrm{mM}$ ), at $\mathrm{pH} 7$ (Figure $2 \mathbf{b}$, S10 and S11) and pH 5 (Figures 2c, S12 and S13). 

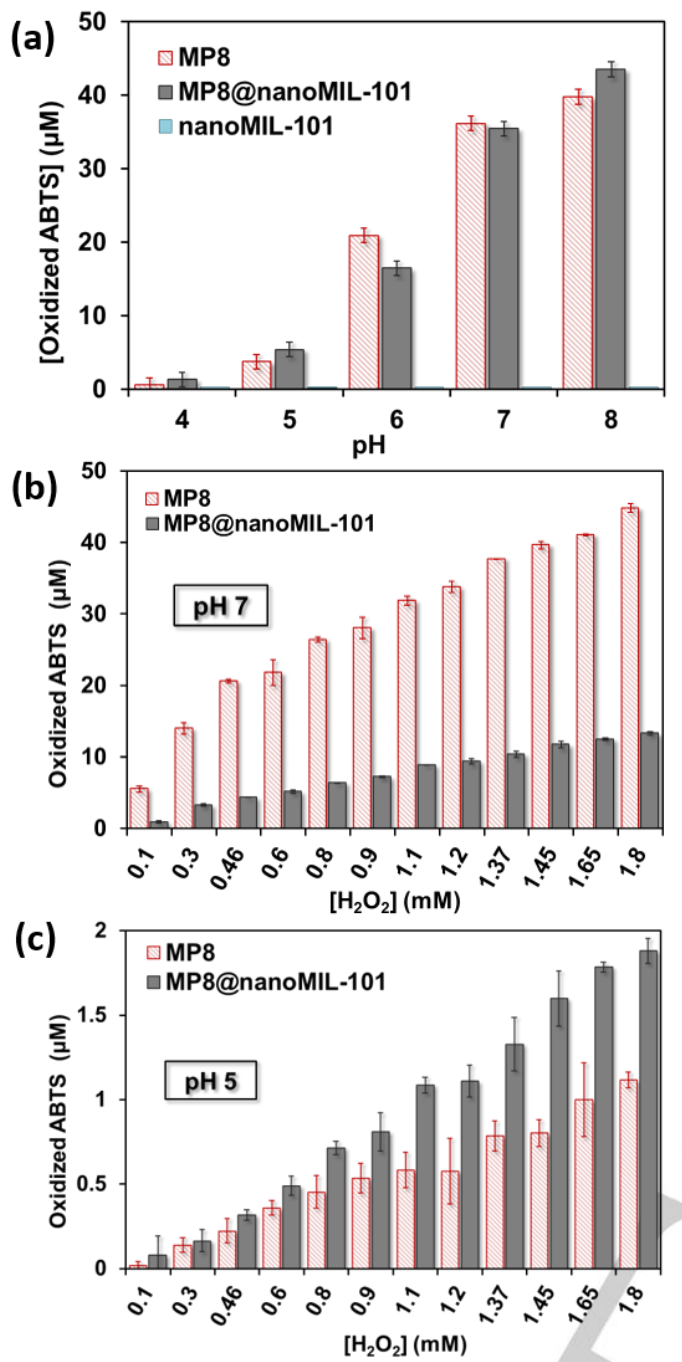

Figure 2. (a) Catalytic oxidation of ABTS after $180 \mathrm{~s}$ as a function of $\mathrm{pH}$ by free MP8 (red), immobilized MP8@nanoMIL101 (grey) and nanoMIL-101 (blue); (b) catalytic oxidation of ABTS after $300 \mathrm{sec}$ as a function of $\mathrm{H}_{2} \mathrm{O}_{2}$ at pH 7 by free MP8 (red), immobilized MP8@nanoMIL101 (grey); (c) catalytic oxidation of ABTS after $300 \mathrm{~s}$ as a function of $\mathrm{H}_{2} \mathrm{O}_{2}$ at pH 5 by free MP8 (red), immobilized MP8@nanoMIL101 (grey). Error bars are the standard deviation of three measurements.

At $\mathrm{pH}$ 7, for the entire $\mathrm{H}_{2} \mathrm{O}_{2}$ range, in 300 seconds, higher amounts of ABTS were obtained with free MP8, as shown in Figure $\mathbf{2 b}$. The reaction kinetics (Figure $\mathbf{S 1 0}$ and $\mathbf{S 1 1}$ ) were faster for free MP8 with a maximum ABTS ${ }^{+}$amount reached in less than 100 seconds, whereas immobilized MP8@nanoMIL101 did not reach the maximum ABTS $^{+}$amount even after 300 seconds. This was attributed to slower diffusion of the substrate to the immobilized enzyme, in accordance with numerous reports on bio-immobilization matrices. ${ }^{[2]}$ However, for a longer period of time ( 1 hour) at high $\mathrm{H}_{2} \mathrm{O}_{2}$ concentration $(0.9 \mathrm{mM})$ displayed in Figure S14, a higher amount of $\mathrm{ABTS}^{++}$was obtained for immobilized MP8@nanoMIL-101, exceeding the amount attained with the free MP8. Such results are consistent with a possible oxidative degradation of the heme moiety of the free MP8 while the active site of the encapsulated MP8 is preserved. At $\mathrm{pH} 5$, the protonation of the histidine coordinated to the heme-Fe in axial position (Figure 1) leads to the cleavage of the Fe-histidine bond, thereby reducing the MP8 catalytic activity. The improved catalytic activity of the MP8@nanoMIL101 at pH 5 clearly suggests that the MIL-101 matrix provides an efficient protection for MP8 outside its optimum $\mathrm{pH}$ range. As already reported, ${ }^{[21]}$ the enzyme encapsulation may provide a confined micro-environment with lower proton concentrations, which likely limits the protonation of the axial histidine of MP8.

The possibility of recycling the material was also evaluated. Since the separation of free MP8 from the reaction mixture is not possible, the activity of free MP8 was not maintained after 1 cycle. As displayed in Figure 3a, 66\% of the initial activity of MP8@nanoMIL-101 was preserved after 5 catalytic cycles.
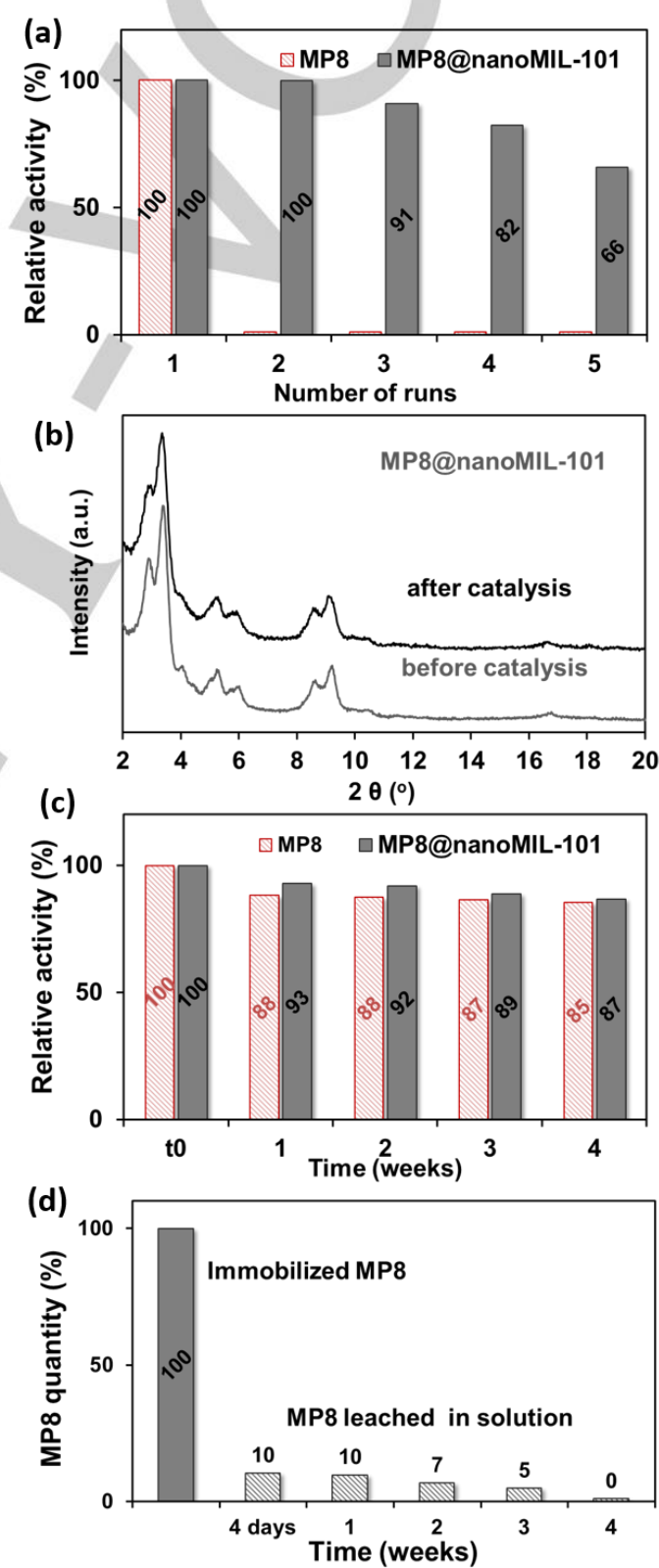

Figure 3. (a) Relative catalytic activity of MP8@nanoMIL-101 over 5 catalytic cycles; (b) PXRD of MP8@nanoMIL-101 before and after 5 catalytic cycles; (c) Stability of free MP8 and immobilized MP8@MIL101 over time (d) Amount of MP8 leached from the MP8@MIL101 material over one month. 
The PRXD pattern of MP8@nanoMIL-101 after the 5 catalytic cycles, in Figure $\mathbf{3 b}$, shows the preservation of the MOF framework. The long-term stability of the material, stored at $4{ }^{\circ} \mathrm{C}$, was assessed over 1 month both in terms of catalytic activity and stability (experimental details are given in $\mathrm{SI}$ ). The results, shown in Figures 3c and 3d, demonstrate a minimal loss of catalytic activity over time (less than $15 \%$ ) as well as minimal leaching of MP8 that stabilizes after a week to reach a cumulated amount of $32 \%$ after 4 weeks (determined from UVVis spectra of the supernatant).

Further catalytic experiments were performed toward the oxidative degradation of model organic dyes. Dyes with different electrostatic charges were selected: cationic Methylene Blue (MB), neutral Sudan II and anionic Methyl Orange (MO)), as shown in Figure 4 and $\mathbf{S 1 5}$. The separation of MB/MO mixtures have previously been reported with various MOFs, including MIL-101(Cr). ${ }^{[22]}$ These dyes have similar molecular sizes but opposite electrostatic charges, their separation has been mainly attributed to the difference of electrostatic affinity with the charged MOF framework. MIL-101 framework is positively charged within the 5-7 $\mathrm{pH}$ range, and therefore selectively absorbs the negatively charged $\mathrm{MO}$ over the positively charged
MB. Thus our idea was to determine if coupling the adsorption selectivity of the MOF matrix with the MP8 oxidative catalytic activity could lead to an enhanced dye degradation process with high substrate selectivity. The catalytic activity of MP8@MIL-101 towards the oxidation of $\mathrm{MB}$, Sudan II and $\mathrm{MO}$ was thus, investigated (Figures 4 and S15). For the oxidation of the positively charged dye (MB, Figure $4 a)$, the reaction rate observed with immobilized MP8@MIL101(Cr) was almost negligible when compared to that observed with free MP8. On the contrary, similar experiments carried out with negatively charged dye (MO, Figure $\mathbf{4 b}$ ) led to much higher reaction rates compared with the free MP8. This can be explained by the electrostatic attractive interactions between $\mathrm{MO}$ and the MOF matrix, while repulsive interactions are expected between $M B$ and MIL-101(Cr) This may strongly favour $d$ of MB within the pores of the MOF, leading to a pre-concentration of $\mathrm{MO}$ at the vicinity of the enzyme. The reaction rate for the neutral dye (Sudan II) was similar for free and immobilized MP8 (Figure S15) in agreement with the much lower affinity with MIL-101(Cr). Hence, the MOF matrix contributes to the material's overall catalytic activity by providing a charge-based selective adsorption of reactants, leading to enhanced reaction rate. (a)

\section{Methylene Blue}
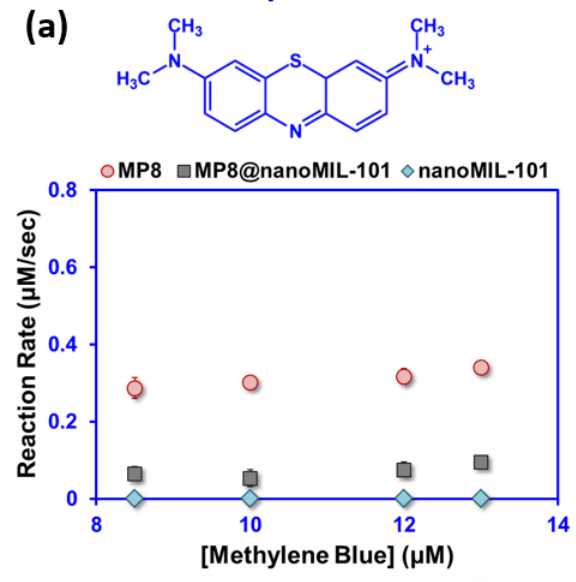

(b)

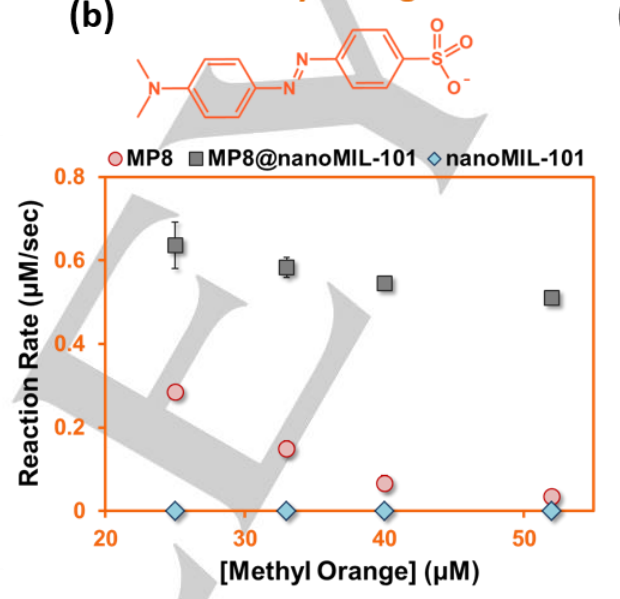

(c)
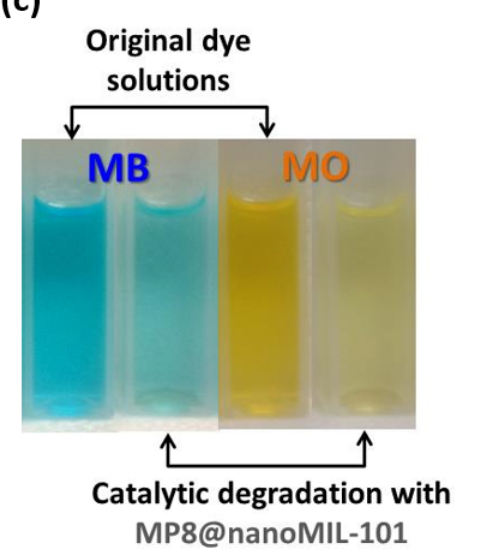

Figure 4. (a) Reaction rate of degradation of Methylene Blue (MB, positive) by free MP8 (red cycles), immobilized MP8@nanoMIL101 (grey squares) and nanoMIL-101 (blue diamonds); (b) Reaction rate of degradation of Methyl Orange (MO, negative) by free MP8 (red cycles), immobilized MP8@nanoMIL101 (grey squares) and nanoMIL-101 (blue diamonds); (c) Solutions of MB and MO before and after the catalytic degradation with MP8@nanoMIL101

In conclusion, we have shown that MP8 could be entrapped and retained in a mesoporous robust MOF with minimal leaching, high catalytic activity and long-term stability. Besides, the entrapped enzyme was protected under acidic or oxidative conditions due to its confinement within the MOF matrix. This work also demonstrated for the first time, that the MOF matrix could act in synergy with the enzyme by selectively enhancing the oxidation reaction of dyes. This was attributed to the preconcentration of reactants due to a charge matching between the dye and the MOF. This work expands the use of MOFs as bio-immobilization matrices beyond simple solids to an active component in catalytic processes.

\section{Experimental Section}

Experimental Details are given in Supplementary Information

\section{Acknowledgements}

This work was supported by the ANR-11-LABEX-0039 (labex charm3at). We thank Dr. M. Benzaqui and C. Livage for the SEM experiments, Dr. A. Tissot for nitrogen adsorption measurements and V. Guerineau for technical assistance in mass spectrometry. 
Keywords: Metal-Organic Frameworks • enzyme • immobilisation $\cdot$ biocatalysis $\cdot$ selectivity

[1] a) G. Rocchitta, A. Spanu, S. Babudieri, G. Latte, G. Madeddu, G. Galleri, S. Nuvoli, P. Bagella, M. I. Demartis, V. Fiore, R. Manetti, P. A. Serra, Sensors 2016, 16, 780; b) O. Kirk, T. V. Borchert, C. C. Fuglsang, Current opinion in biotechnology 2002, 13, 345-351.

[2] a) R. A. Sheldon, S. van Pelt, Chem Soc Rev 2013, 42, 6223-6235; b) M. Hartmann, X. Kostrov, Chem Soc Rev 2013, 42, 6277-6289; c) Z. Zhou, M. Hartmann, Chem Soc Rev 2013, 42, 3894-3912; d) H. H. P. Yiu, P. A Wright, J Mater Chem 2005, 15, 3690-3700; e) D. Avnir, T. Coradin, O Lev, J. Livage, J Mater Chem 2006, 16, 1013-1030; f) E. M. Forsberg, C. Sicard, J. D. Brennan, Annu Rev Anal Chem 2014, 7, 337-359.

[3] a) V. Lykourinou, Y. Chen, X.-s. Wang, L. Meng, T. Hoang, L.-j. Ming, R. L. Musselman, S. Ma, J. Am. Chem. Soc. 2011, 133, 10382-10385; b) H. Deng, S. Grunder, K. E. Cordova, C. Valente, H. Furukawa, M. Hmadeh, F. Gandara, A. C. Whalley, Z. Liu, S. Asahina, H. Kazumori, M. O'Keeffe, O. Terasaki, J. F. Stoddart, O. M. Yaghi, Science 2012, 336, 1018-1023 c) F. Lyu, Y. Zhang, R. N. Zare, J. Ge, Z. Liu, Nano Lett 2014, 14, 5761 5765; d) K. Liang, R. Ricco, C. M. Doherty, M. J. Styles, S. Bell, N. Kirby, S. Mudie, D. Haylock, A. J. Hill, C. J. Doonan, P. Falcaro, Nat Commun 2015, 6, 7240; e) D. Feng, T. F. Liu, J. Su, M. Bosch, Z. Wei, W. Wan, D. Yuan, Y. P. Chen, X. Wang, K. Wang, X. Lian, Z. Y. Gu, J. Park, X. Zou, H. C. Zhou, Nat Commun 2015, 6, 5979; f) J. Huo, J. Aguilera-Sigalat, S. El-Hankari, D. Bradshaw, Chemical science 2015, 6, 1938-1943.

[4] a) G. Maurin, C. Serre, A. Cooper, G. Ferey, Chem. Soc. Rev. 2017, 46, 3104-3107; b) H. Furukawa, K. E. Cordova, M. O'Keeffe, O. M. Yaghi, Science 2013, 341, 1230444; c) K. Adil, Y. Belmabkhout, R. S. Pillai, A. Cadiau, P. M. Bhatt, A. H. Assen, G. Maurin, M. Eddaoudi, Chem Soc Rev 2017, 46, 3402-3430; d) M. F. de Lange, K. J. Verouden, T. J. Vlugt, J. Gascon, F. Kapteijn, Chemical reviews 2015, 115, 12205-12250; e) M. Giménez-Marqués, T. Hidalgo, C. Serre, P. Horcajada, Coordination Chemistry Reviews 2016, 307, 342-360; f) L. E. Kreno, K. Leong, O. K. Farha, M. Allendorf, R. P. Van Duyne, J. T. Hupp, Chemical reviews 2012 112, 1105-1125; g) P. García-García, M. Müller, A. Corma, Chemical science 2014, 5, 2979.

[5] a) E. Gkaniatsou, C. Sicard, R. Ricoux, J. P. Mahy, N. Steunou, C. Serre, Mater Horiz 2017, 4, 55-63; b) C. Doonan, R. Ricco, K. Liang, D. Bradshaw, P. Falcaro, Acc Chem Res 2017, 50, 1423-1432; c) X. Lian, Y. Fang, E. Joseph, Q. Wang, J. Li, S. Banerjee, C. Lollar, X. Wang, H. C Zhou, Chem Soc Rev 2017, 46, 3386-3401; d) M. B. Majewski, A. J. Howarth, P. Li, M. R. Wasielewski, J. T. Hupp, O. K. Farha, CrystEngComm 2017, 19, 4082-4091.

[6] a) P. Li, J. A. Modica, A. J. Howarth, E. L. Vargas, P. Z. Moghadam, R. Q. Snurr, M. Mrksich, J. T. Hupp, O. K. Farha, Chem 2016, 1, 154-169; b) S. Patra, S. Sene, C. Mousty, C. Serre, A. Chausse, L. Legrand, N. Steunou, ACS applied materials \& interfaces 2016, 8, 20012-20022; c) P. Li, Q. Chen, T. C. Wang, N. A. Vermeulen, B. L. Mehdi, A. Dohnalkoya, N. D. Browning, D. Shen, R. Anderson, D. A. Gomez-Gualdron, F. M. Cetin, J. Jagiello, A. M. Asiri, J. F. Stoddart, O. K. Farhal, Chem 2018, 4, 1022 1034.

[7] a) Y. Chen, V. Lykourinou, T. Hoang, L. J. Ming, S. Ma, Inorg Chem 2012 51, 9156-9158; b) F. K. Shieh, S. C. Wang, C. I. Yen, C. C. Wu, S. Dutta L. Y. Chou, J. V. Morabito, P. Hu, M. H. Hsu, K. C. Wu, C. K. Tsung, J Am Chem Soc 2015, 137, 4276-4279.
[8] a) A. M. Osman, M. A. Posthumus, C. Veeger, P. J. van Bladeren, C. Laane, I. M. Rietjens, Chemical research in toxicology 1998, 11, 13191325; b) R. Ricoux, J. L. Boucher, D. Mansuy, J. P. Mahy, European journal of biochemistry 2001, 268, 3783-3788.

[9] ) O. Q. Munro, H. M. Marques, Inorganic Chemistry 1996, 35, 3752-3767.

[10] ) T. Robinson, G. Mcmullan, R. Marchant, P. Nigam, Bioresour Technol 2001, 77, 247-255.

[11] ) J. Aron, D. A. Baldwin, H. M. Marques, J. M. Pratt, P. A. Adams, Journal of inorganic biochemistry 1986, 27, 227-243.

[12] ) G. Ferey, C. Mellot-Draznieks, C. Serre, F. Millange, J. Dutour, S. Surble, I. Margiolaki, Science 2005, 309, 2040-2042.

[13] ) P. X. Qi, R. A. Beckman, A. J. Wand, 1996, 2960, 12275-12286.

[14] ) Y. Chen, V. Lykourinou, C. Vetromile, T. Hoang, L.-j. Ming, R. W. Larsen, S. Ma, J. Am. Chem. Soc. 2012, 134, 13188-13191.

[15] ) A. Demessence, P. Horcajada, C. Serre, C. Boissière, D. Grosso, Chem Commum 2009, 101, 7149-7151.

[16] ) P. Li, S. Y. Moon, M. A. Guelta, L. Lin, D. A. Gomez-Gualdron, R. Q. Snurr, S. P. Harvey, J. T. Hupp, O. K. Farha, ACS nano 2016.

[17] ) S. D. Lauzon, D. Mansuy, J.-p. Mahy, 2002, 480, 470-480.

[18] ) S. Othman, A. Le Lirzin, A. Desbois, Biochem 1994, 33, 15437-15448.

[19] ) E. N. Kadnikova, N. M. Kostic, J Mol Catal B-Enzym 2002, 18, 39-48.

[20] a) J.-s. Wangs, A.-I. Tsaig, J. Heldts, G. Palmer, E. V. Wartsii, J Biol Chem 1992, 267, 15310-15318; b) J. Cheek, D. W. Low, H. B. Gray, J. H. Dawson, Biochem Biophys Res Commun 1998, 253, 195-198.

[21] ) H. Frenkel-Mullerad, D. Avnir, J Am Chem Soc 2005, 127, 8077-8081.

[22] a) E. Haque, J. W. Jun, S. H. Jhung, J Hazard Mater 2011, 185, 507-511; b) M. M. Tong, D. H. Liu, Q. Y. Yang, S. Devautour-Vinot, G. Maurin, C. L. Zhong, J Mater Chem A 2013, 1, 8534-8537; c) Q. X. Yang, S. S. Ren, Q. Q. Zhao, R. Lu, C. Hang, Z. J. Chen, H. G. Zheng, Chem Eng J 2018, 333, 49-57. 


\section{Entry for the Table of Contents}

\section{COMMUNICATION}

Microperoxidase-8, was immobilized into nanoparticles of the mesoporous and ultra-stable MIL-101(Cr).exhibiting enhanced resistance to acidic media. The oxidation rate of the harmful negatively charged methyl orange was significantly increased after enzyme immobilization.

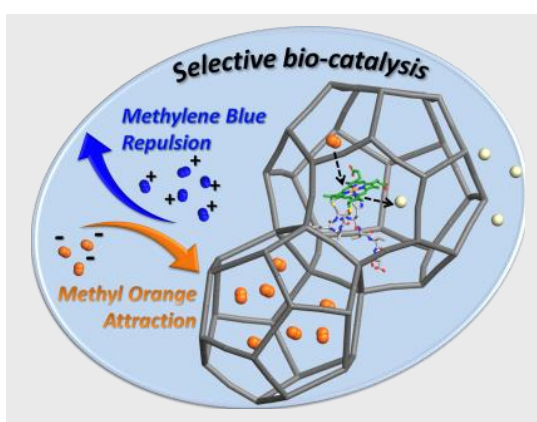

Effrosyni Gkaniatsou, Clémence Sicard, * Rémy Ricoux, Linda Benahmed, Flavien Bourdreux, Qi Zhang, Christian Serre, Jean-Pierre Mahy, Nathalie Steunou

Page No. - Page No.

Enzyme encapsulation in MetalOrganic Frameworks for selective biodegradation of harmful charged dye molecules 